\title{
Rs739837 Polymorphism in MiR-885-3p Binding Site Within 3'-Untranslated Region of Vitamin D Receptor is Associated with a Decreased Risk of Pressure Ulcers
}

\author{
Xia Jia Jinbao Mao ${ }^{\mathrm{b}}$ Shuang Zhou ${ }^{\mathrm{c}}$ \\ aperation room, Dezhou People's Hospital, 'OOperation room, Shandong Provincial Hospital Affiliated \\ to Shandong University, 'Operation room, Liaocheng People's Hospital, Liaocheng, China
}

\section{Key Words}

Rs739837 • MiR-885-3p • 3'-UTR • VDR • Pressure ulcers

\begin{abstract}
Background/Aims: Accumulative evidence has shown that miR-885-3p plays a crucial role in human carcinogenesis. From miRNA database, we also found that rs739837 polymorphism in miR-885-3p binding site within 3'-untranslated region of Vitamin D receptor (VDR), compromising the suppressive effect of miR-885-3p on VDR. Moreover, Vitamin D is involved in controlling the cell immune response and may play a role in pressure ulcers development. However, whether this polymorphism is actually linked with pressure ulcers remains unclear. The aim of the present study was to investigate the potential association between the rs 739837 polymorphism and pressure ulcers, and to explore molecular mechanism of VDR in pressure ulcers. Methods: Luciferase assays were performed to validate the relationship between miR885 and VDR, which was confirmed by western-blotting analysis. The relationship between rs739837 and the risk of pressure ulcers was explored using logistic regression analysis. Results: We first conducted statistical analysis to explore the association between the rs739837 genotype and risk of pressure ulcers, and found that the polymorphism genotype was significantly associated with the risk of pressure ulcers_(OR $0.68,95 \%$ CI $0.43-0.95$, P value $=0.02$ ). We then searched the miRNA database online and identified VDR as a direct target. We established the negative regulatory relationship between miR-885-3p and VDR using luciferase assays. Meanwhile, we transfected cells with scramble control, miR-885-3p mimics, VDR siRNA and miR-885-3p inhibitors. The results further confirmed the negative regulatory relationship between miR-885-3p and VDR. Conclusion: VDR is a virtual target of miR-885-3p, and rs739837 might be a predictive biomarker for the risk of pressure ulcers.
\end{abstract}




\section{Cellular Physiology Cell Physiol Biochem 2017;44:2129-2137 \begin{tabular}{l|l|l} 
and Biochemistry Published online: December 12, 2017 & $\begin{array}{l}\text { (c) } 2017 \text { The Author(s). Published by S. Karger AG, Basel } \\
\text { www.karger.com/cpb }\end{array}$ \\
\hline
\end{tabular}

\section{Introduction}

A pressure ulcer is defined as a "localized skin injury caused by pressure or pressure together with shear [1]. Risk factors include physical impairment, cognitive impairment, age and comorbid conditions (including malnutrition, hypoalbuminemia, impaired microcirculation, edema and urinary incontinence) that hamper the healing and integrity of soft tissue [2, 3]. In the United States, 1.3 million to 3 million adults are affected by pressure ulcers, which are associated with impaired function, decreased quality of life and complications, such as a cost-of-care increase, poor prognosis and infection [3-6]. As a kind of fat-soluble nutrient, vitamin D is synthesized in the skin when the skin is exposed to ultraviolet light. The VDR was discovered in the 1970s. By measuring the levels of titrated 1,25-dihydroxyvitamin D3 (the active form of vitamin D) in the target nucleus and by immunochemistry, vitamin $\mathrm{D}$, whose presence showed no significant association with phosphorus and calcium metabolism, was confirmed to exist in numerous organs [7]. Receptors of vitamin D have been detected in dermal papilla cells, sebocytes and keratinocytes, and the skin is recognized as a target organ of vitamin D [8-10]. Vitamin D is involved in controlling the cell immune response, differentiation and proliferation, and vitamin D participates in terminal differentiation of the epidermal cell in vitro [11, 12]. Vitamin D might play a role in skin maintenance and pressure ulcer development. Most of the biological activities of vitamin D presumably function via VDR (vitamin D receptor)-mediated control of target genes. VDR is part of the nuclear hormone receptor super-family and serves as a ligand-inducible transcription factor. Because ligand-induced VDR actions are involved in transactivation, co-activator complexes have recently been shown to be essential [13]. MicroRNAs (miRNAs) are drawing increasing attention as they have remarkably important functions in numerous biological processes such as stress responses, cell apoptosis, differentiation, proliferation, cancer initiation and cancer progression [1419]. As small noncoding RNAs, miRNAs regulate the expression of a wide range of genes in a post-transcriptional manner, leading to silencing RNA complexes with several proteins to induce translational inhibition, degradation of mRNA, or both $[14,18]$. By searching an online miRNA database (http://www.bioguo.org/miRNASNP2/index. php), we found that miR-885-3p virtually targeted VDR and that one single nucleotide polymorphism (rs739837) located in the 3'UTR of VDR disrupted binding between miR885-3p and the 3'UTR of VDR, compromising the suppressive effect of miR-885-3p on VDR. Rs7975232 (Apa1), rs2228570 (Fok1), rs739837 (Bgl1) and rs1544410 (Bsm1) are extensively studied VDR polymorphisms. Rs7975232 and rs739837 are restriction fragment length polymorphisms that correspond to G/T and G/T substitutions, respectively [20]. The rs739837 polymorphism is located within 303 base-pairs downstream of the exon 9 stop codon. In addition, the presence of the $C$ allele in rs739837 has been shown to create a binding site for miRNA-34b, may decrease $V D R$ gene expression through an altered binding affinity to microRNAs, and causes inhibition of post-transcriptional regulation [15]. Thus, we hypothesize that there may be a relationship between pressure ulcer development and the presence of rs739837. To determine the association between pressure ulcer development and the rs739837 genotype, we carried out a gender-matched and age-matched case-control study.

\section{Materials and Methods}

\section{Participants}

Participants (293 with pressure ulcers and 276 without pressure ulcers) were randomly recruited from Dezhou People's Hospital and Linyi people's Hospital. The cases comprised patients with pressure ulcers and the control group was selected to include subjects matched by age and gender. We excluded patients with skin ulcers that were caused by factors other than pressure. The demographic and clinicopathological characteristics of both study groups are described in Table 1 . The diagnosis of pressure ulceration was made by clinicians and documented in the bill and/or medical record as a pressure ulcer. In addition, 38 tissue 


\section{Cellular Physiology Cell Physiol Biochem 2017;44:2129-2137 \begin{tabular}{l|l} 
DOI: 10.1159/000485952 & $\begin{array}{l}\text { O } 2017 \text { The Author(s). Published by S. Karger AG, Basel } \\
\text { www.karger.com/cpb }\end{array}$
\end{tabular} \\ Ji et al.: Rs739837 and the Risk of Pressure Ulcers}

Table 1. The demographic and clinicopathological characteristics of the participants in this study

\begin{tabular}{|c|c|c|c|}
\hline Variable & Controls & Cases & P value \\
\hline & $(n=276)$ & $(n=293)$ & \\
\hline Age (years) & $75.23 \pm 9.12$ & $76.13 \pm 8.62$ & NS \\
\hline 25-hydroxyvitamin D (ng/mL) & $34.23 \pm 15.34$ & $33.25 \pm 17.43$ & NS \\
\hline Male gender, $\mathrm{n}$ & 156 & 168 & NS \\
\hline Myocardial infarction, $\mathrm{n}$ & 36 & 42 & NS \\
\hline Congestive heart failure, $\mathrm{n}$ & 39 & 46 & NS \\
\hline Peripheral vascular disease, $\mathrm{n}$ & 32 & 38 & NS \\
\hline Cerebrovascular disease, $\mathrm{n}$ & 64 & 72 & NS \\
\hline Dementia, n & 15 & 21 & NS \\
\hline Chronic pulmonary disease, $\mathrm{n}$ & 83 & 95 & NS \\
\hline Liver disease, $n$ & 12 & 15 & NS \\
\hline Diabetes, n & 65 & 76 & NS \\
\hline Diabetic end organ damage, $n$ & 32 & 36 & NS \\
\hline Hemiplegia, n & 14 & 16 & NS \\
\hline Renal failure, $\mathrm{n}$ & 34 & 37 & NS \\
\hline Rheumatoid arthritis, n & 42 & 47 & NS \\
\hline Cancer, n & 83 & 98 & NS \\
\hline \multicolumn{4}{|l|}{ Rs739837 genotype GG } \\
\hline $\cos$ & $\begin{array}{l}147 \\
107\end{array}$ & $\begin{array}{l}183 \\
98\end{array}$ & OR: 0.68 \\
\hline TT & 22 & 12 & $95 \%$ CI $(0.43-0.95)$ \\
\hline $\mathrm{TG}+\mathrm{TT}$ & 129 & 110 & $\mathrm{P}=0.02$ \\
\hline
\end{tabular}

samples were collected from the patients diagnosed with pressure ulcers and genotyped for rs739837. The study protocol was approved by the ethics research committee at Linyi people's Hospital, and written consent was obtained from each participant.

\section{Genotyping}

Tiangen Relax Gene Blood DNA System (Tiangen Biotech, Beijing, China) was used to extract genomic DNA in accordance with the manufacturer's recommendations. The technicians who processed the samples were blinded to the identities of the subjects in the control and sample groups. The TaqMan allelic discrimination assay was performed on a 7900HT real-time polymerase chain reaction system (Applied Biosystems, Foster City, CA, USA) to carry out genotyping without knowledge of the patients' statuses. SDS 2.3 Allelic Discrimination software (Applied Biosystems, Foster City, CA, USA) was used to analyze the genotyping results based on a standard protocol. Each test was run in triplicate.

\section{Reverse transcription-quantitative polymerase chain reaction (RT-qPCR)}

Total RNA from cultured CRL-2522 cells and tissues samples was extracted using an RNA extraction kit (Thermo Fisher Scientific, Waltham, MA, USA) in accordance with the manufacturer's instructions. The M-MLV RTase cDNA synthesis kit (Takara, Dalian, China) was used to synthesize first strand cDNA from the extracted RNA per the guideline of the supplier. We extracted miRNA using a mirPremier ${ }^{\circledR}$ microRNA isolation kit (Sigma-Aldrich, St Louis, MO., USA), and the miRNA extracts were subsequently subjected to reverse transcription with the QuantiTect reverse transcription kit (QIAGEN, Shanghai, China) based on the standard protocol. TaqMan Universal Master Mix II (2X) (Applied Biosystems, Foster City, CA, USA) was used to amplify the target miRNA. A TaqMan expression detection kit (Applied Biosystems, Foster City, CA, USA) was utilized to quantify the expression levels of miR-855 and VDR. qPCR thermal cycling was carried out on the $\mathrm{CFX} 6^{\mathrm{Tm}}$ Real-Time PCR Detection system (Bio-Rad, Hercules, CA, USA) at $95^{\circ} \mathrm{C}$ for $10 \mathrm{~min}$ for the initial denaturation, followed by 30 cycles of $95^{\circ} \mathrm{C}$ for $20 \mathrm{~s}, 58^{\circ} \mathrm{C}$ for $30 \mathrm{~s}$ and $72^{\circ} \mathrm{C}$ for $25 \mathrm{~s}$, an extension at $72^{\circ} \mathrm{C}$ for $5 \mathrm{~min}$ and a hold at $4^{\circ} \mathrm{C}$. All data were shown as the fold change, and the $2^{-\Delta \Delta \mathrm{Ct}}$ method was used to interpret the results of gene expression. Each sample was performed in triplicate. 


\section{Cellular Physiology Cell Physiol Biochem 2017;44:2129-2137 \begin{tabular}{ll|l} 
and Biochemistry Published online: December 12, 2017 & $\begin{array}{l}\text { C } 2017 \text { The Author(s). Published by S. Karger AG, Basel } \\
\text { www.karger.com/cpb }\end{array}$ \\
\hline
\end{tabular} \\ Ji et al.: Rs739837 and the Risk of Pressure Ulcers}

\section{Western blot analysis}

CRL-2522 cells were prepared with the following procedure. PBS (phosphate-buffered saline) was used to wash the cells twice on ice. Lysis buffer (Applied Biosystems, Foster City, CA, USA), supplemented with protease inhibitors, $150 \mathrm{mmol} / \mathrm{L} \mathrm{NaCl}, 1 \mathrm{mmol} / \mathrm{L}$ EDTA, 1\% Triton X-100, $1 \mathrm{mmol} / \mathrm{L}$ EGTA, $2 \mathrm{~mol} / \mathrm{L}$ $\mathrm{Na}_{3} \mathrm{VO}_{4}, 0.1 \%$ SDS (sodium dodecyl sulfate), 10\% glycerol, $20 \mathrm{~mol} / \mathrm{L} \mathrm{Na}_{4} \mathrm{P}_{2} \mathrm{O}_{7}, 1 \mathrm{mmol} / \mathrm{L} \mathrm{PMSF}, 2 \mu \mathrm{g} / \mathrm{mL}$ leupeptin, $20 \mathrm{mmol} / \mathrm{L}$ Tris- $\mathrm{HCl}(\mathrm{pH} 7.5)$, was used to lyse the cells to obtain protein in accordance with the manufacturer's instructions. The lysates were subjected to centrifugation at $4^{\circ} \mathrm{C}$ at $15000 \mathrm{rpm}$ for 10 min to collect the supernatants. The BCA (Bicinchoninic Acid) kit (Sigma-Aldrich, St Louis, MO, USA) was used to determine the protein concentrations per the supplier's protocol. For western blotting, the cellular protein extracts were loaded onto 10\% SDS-PAGE (sodium dodecyl sulfate polyacrylamide gel electrophoresis) gels. After electrophoresis, the proteins were transferred to polyvinylidene fluoride (PVDF) membranes (Millipore, Bedford, MA, USA). To detect the target proteins, membranes were incubated with primary antibodies, namely, anti-VDR (1:2000, Cell Signaling Technology, Beverly, MA, USA) and anti- $\beta$-actin (1:10000, Abcam, Cambridge, MA, USA), for 18 hours at $4^{\circ}$ C. The membranes were then incubated with horseradish peroxidase-linked anti-rabbit secondary antibodies (1:15000, Santa Cruz Biotechnology, Santa Cruz, CA, USA) at room temperature for $60 \mathrm{~min}$. The ECL chemiluminescent kit (Thermo Scientific, Rockford, IL, USA) was used to visualize the blotted bands, and the ChemiDoc ${ }^{\mathrm{TM}} \mathrm{XRS}+$ imaging system (Bio-Rad, CA, USA) was used to quantify the relative expression of VDR normalized to the expression of $\beta$-actin.

\section{Cell transfection}

Lipofectamine 2000 (Invitrogen, CA, USA) was used to transfect CRL-2522 cells with the scramble control, miR-855-3P mimic or inhibitor, and VDR siRNA in accordance with the manufacturer's guidelines. Briefly, cells were maintained in $10 \% \mathrm{FBS}$, incubated in 48 -well plates at $37^{\circ} \mathrm{C}$, cultured for $15 \mathrm{~min}$ at room temperature, seeded into 24-well plates, incubated for 24 hours, and starved for 18 hours. Subsequently, the cells were transfected with the scramble control, miR-855-3P mimic, VDR siRNA or miR-855-3P inhibitor for 2 days in medium supplemented with FBS. Finally, cells were harvested, and miRNA, total RNA, and total protein were isolated for the subsequent analyses.

\section{Luciferase assay}

PCR was used to amplify the wild-type and mutant VDR 3'UTRs with the putative binding sites of miR-855-3P, and the PCR products were inserted into pmiRGLO vectors (Promega, Madison, WI, USA). PCR amplifications were performed to confirm the inserts. Lipofectamine 2000 (Invitrogen, CA, USA) was used to co-transfect the cells with scramble control, miR-855-3P mimic or inhibitor and the wild-type (WT) or mutant (Mut) 3'-UTR vectors in accordance with the manufacturer's instructions. Luciferase activity was measured with the Dual Luciferase Reporter Assay system (Promega, Madison, WI, USA) 48 hours posttransfection. Firefly luciferase activity was normalized to Renilla luciferase activity. All experiments were repeated at least three times.

\section{Statistical analysis}

All data were shown as the means \pm SD (standard deviation). Student's t-test was used to perform comparisons between two groups, and one-way analysis of variance was used to perform comparisons between multiple groups. In addition, categorical variables were investigated using Fisher's exact test or the chi-square test, and covariates were adjusted by multiple logistic regression. SPSS version 13.0 (SPSS, Inc, Chicago, IL, USA) was used to analyze the statistical data. Fisher's exact test or the chi-square test was used to assess the HWE (Hardy-Weinberg equilibrium) with the HWE program as the control. $\mathrm{P}<0.05$ was considered statistically significant.

\section{Results}

Demographic, clinicopathological and genotypic parameters of the participants recruited in this study

We divided the participants into two groups: the case group and the control group. We then performed Student's t-test to evaluate the differences in age, serum 25-hydroxyvitamin D levels, congestive heart failure, myocardial infarction, cerebrovascular disease, dementia, 


\section{Cellular Physiology Cell Physiol Biochem 2017;44:2129-2137 \begin{tabular}{l|l|l} 
and Biochemistry & DOI: 10.1159/000485952 & $\begin{array}{l}\text { C } 2017 \text { The Author(s). Published by S. Karger AG, Basel } \\
\text { www.karger.com/cpb }\end{array}$
\end{tabular} \\ Ji et al.: Rs739837 and the Risk of Pressure Ulcers}

Fig. 1. VDR as the candidate target gene of miR-885-3p in cells with the 'seed sequence' in the 3'UTR.

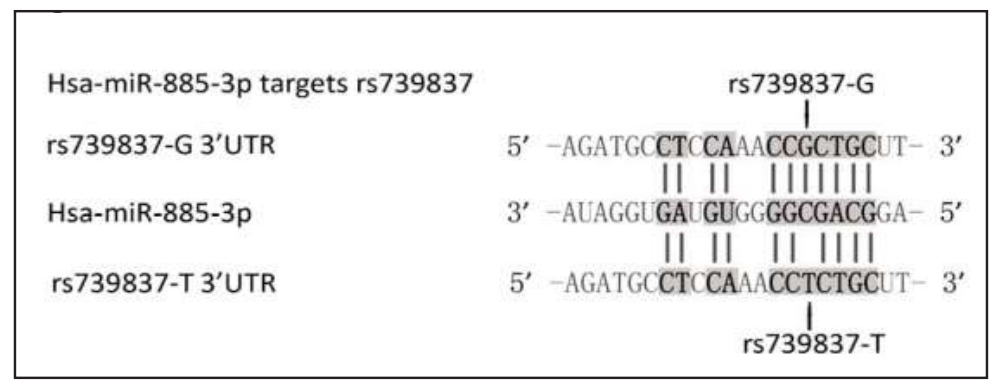

peripheral vascular disease, chronic pulmonary disease, diabetes, liver disease, diabetic end organ damage, renal failure, hemiplegia, rheumatoid arthritis and cancer between the two groups. As shown in Table 1, no statistically significant differences were evident between any of the variables. The participants were divided into three groups based on the Rs739837 genotype. In the control group, 147 were GG, 107 were TG, 22 were TT and 129 were $\mathrm{TG}+\mathrm{TT}(107+22)$. In the case group, 183 were GG, 98 were TG, 12 were TT and 110 were TG+TT (98+12). Logistic regression analysis was then performed, and the results showed that the polymorphism genotype was remarkably associated with the development and progression of pressure ulcers (OR $0.68,95 \%$ CI 0.43 $0.95, \mathrm{P}=0.02$ ). In addition, the genotype of the polymorphism abided by the HWE.

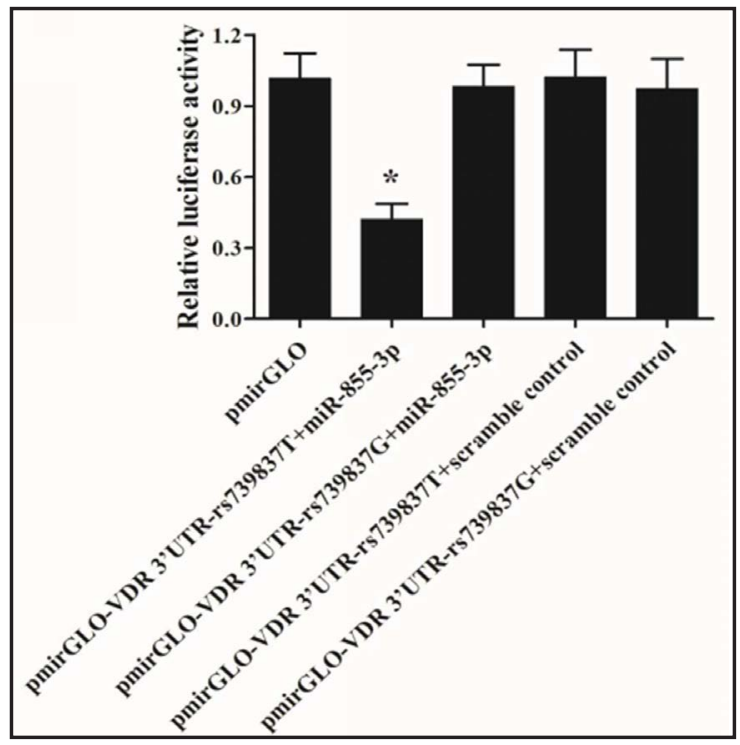

Fig. 2. Luciferase activity reporter assay was conducted to verify VDR as the direct target gene of miR-885$3 p$.

\section{VDR was virtual target of miR-885-3p}

MiR-885-3p has been reported to be involved in many diseases, such as colon cancer. To understand the role of miR-885-3p in patients with pressure ulcers, we used online miRNA target prediction tools to search the regulatory genes of miR-885-3p and consequently identified VDR as a candidate target gene of miR-885-3p in cells with a complementary sequences-in the seed region of miR-885 (i.e., at the 2-7 nucleotide position away from the 5' end of the miRNA) with the sequences in the 3'UTR of VDR (Fig. 1). Furthermore, to validate the regulatory relationship between miR-885-3p and VDR, we also conducted luciferase activity reporter assays in CRL-2522 cells. We observed luciferase activity only in the cells transfected with miR-885-3p mimics, wherein the rs739837-T VDR 3'UTR decreased significantly (Fig. 2). However, luciferase activity in the cells co-transfected with miR-885-3p mimics and the rs739837-G VDR 3'UTR was comparable to that of the scramble control (Fig. 2 ). The results confirmed that VDR was a validate target of miR-885-3p in cells.

\section{Determination of expression patterns of miR-885-3p and VDR}

To understand the regulatory relationship between miR-885-3p and VDR, we investigated the mRNA/protein expression levels of VDR in cells. To this end, we transfected CRL-2522 cells with scramble control, miR-885-3p mimics or inhibitors, and VDR siRNA. As shown in Fig. 3, the VDR protein (upper panel) and mRNA expression levels (lower panel) in the cells treated with miR-885-3p mimics and VDR siRNA were apparently lower than the levels in the scramble control cells; however, the levels in cells transfected with miR-885$3 p$ inhibitors were apparently higher than those of the scramble control, and the results 


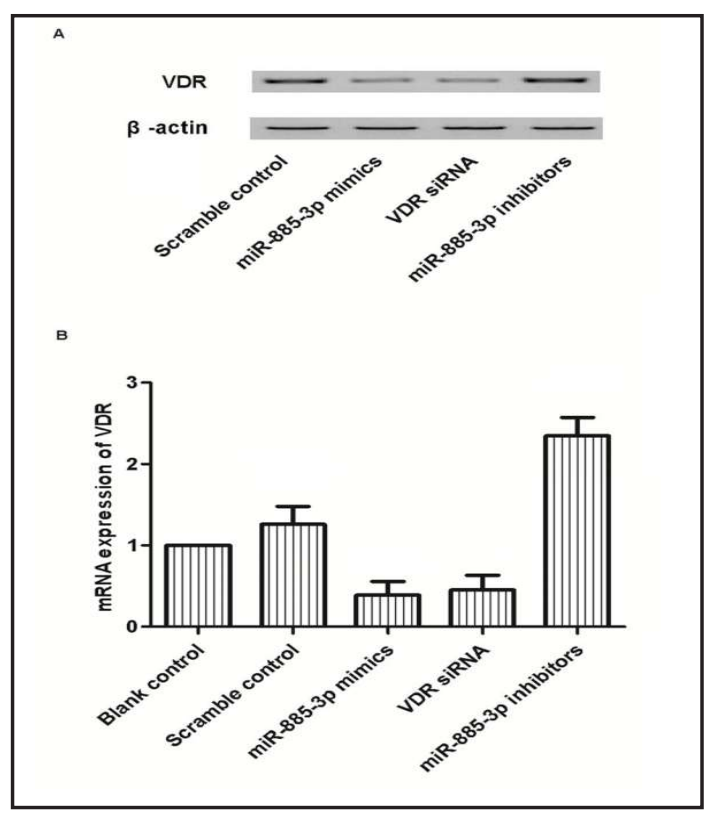

Fig. 3. When transfected with the cells with scramble control, miR-885-3p mimics, VDR siRNA and miR-885-3p inhibitors, the expression level of VDR protein (upper panel) and mRNA (lower panel) treated with miR-885-3p mimics and VDR siRNA decreased, while cells treated miR-885-3p inhibitors increased.

revealed a negative regulatory relationship between miR-885-3p and VDR.

Determination of expression patterns of miR-885-3p, VDR mRNA and protein with different genotypes

The impacts of the rs739837 polymorphism on the expression of miR885-3p, the VDR mRNA and the VDR protein were determined with real-time PCR and western blot analyses. All tissue samples were collected from Dezhou People's Hospital and Linyi people's Hospital, and the genotypes were determined (GG, $n=20$, GT, $n=14$, TT, n=4). Real-time PCR was used to detect the expression of miR-885-3p with different genotypes. As shown in Fig. 4A, the expression of miR-885-3p showed no statistically significant differences among the GG, GT and TT genotypes, suggesting that rs739837 polymorphism is not significantly associated with the expression of miR-885-3p. The results of the real-time PCR and western blot analyses are shown in Fig. 4B and 4C, respectively. The VDR mRNA (Fig. 4B) and VDR protein (Fig. 4C) expression levels in the subjects who carried the rs739837 GT and TT genotypes were similar, and the number of subjects with the GT and TT genotypes was higher than the number subjects with the GG genotype, suggesting that the influence of the rs739837 $\mathrm{T}$ allele on the expression level of miR-885-3p represented a recessive pattern in the highgrade group.

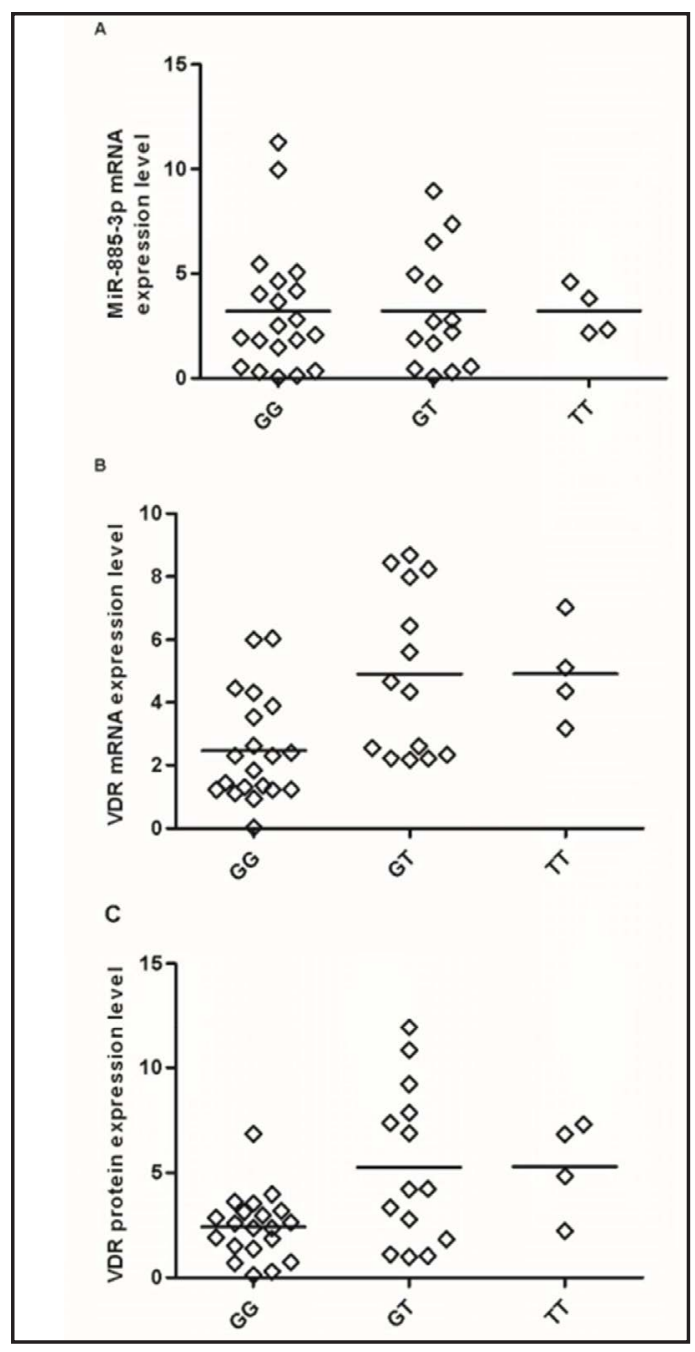

Fig. 4. Real-time PCR and western blot were used to detect the expressions level of miR-885-3P, VDR mRNA and protein; we found that the miR-885-3P expression level in those who carried rs739837 GG genotype was comparable with GT and TT, the VDR mRNA and protein expression levels in those who carried rs739837 GT and TT genotype were similar, and both GT and TT genotype groups were upregulated compared with GG carriers. 


\section{Cellular Physiology Cell Physiol Biochem 2017;44:2129-2137 \begin{tabular}{l|l} 
and Biochemistry & DOI: 10.1159/000485952 \\
(c) 2017 The Author(s). Published by S. Karger AG, Basel \\
www.karger.com/cpb
\end{tabular} Ji et al.: Rs739837 and the Risk of Pressure Ulcers}

The negative regulatory relationship between VDR and miR-885-3p

The miRNA-mRNA regulatory relationship between the expression level of VDR mRNA and the expression of miR885-3p was confirmed by RT-PCR. Based on the results, we confirmed the negative regulatory relationship between miR-885$3 p$ and VDR in accordance with the negative correlation coefficient being -0.5034 , as shown in Fig. 5.

\section{Discussion}

Malnutrition is a recognized hazard for the perpetuation and attack of pressure sores. Similarly, several dietary factors influence ulcer development. Weight loss, low serum albumin and low body mass index are associated with the risk factors of pressure ulcers [21]. Several researchers have confirmed that vitamin $\mathrm{D}$ might be involved in various chronic diseases such as cystic fibrosis, pulmonary arterial hypertension (PAH), interstitial lung disease, chronic obstructive pulmonary disease (COPD), lung cancer, respiratory infections and asthma [22, 23]. As a steroid pre-hormone, the vitamin D precursor undergoes two hydroxylation steps in the liver and kidney where vitamin D3 is turned into the biological active form, known as $1,25(\mathrm{OH}) 2 \mathrm{D} 3$. This form functions by targeting the VDR. Since vitamin D deficiency is also known to be associated with pressure ulceration, we hypothesized that a decrease in the expression of VDR might play a role in the development of pressure ulcers [1]. Unfortunately, no existing reports have described the relationship between pressure ulcers and the VDR. Thus, we conducted this study to demonstrate the relationship between pressure ulceration and VDR.

Considerable proportions of senior adults, including 57\% of hospitalized adult patients with a mean age of 62 years, $44 \%$ of elderly ambulatory women with a mean age of 80 years, and $25 \%-50 \%$ of housebound or nursing home residents, suffer from vitamin D deficiency [24]. Vitamin D studies concerning the health in older people have made significant advances over the past decades [24]. In this study, we collected information on the demographic, clinicopathological and genotypic parameters of a participant cohort, divided the participants into three groups by rs739837 genotype, evaluated the differences between the groups, and found that the association between rs739837 polymorphism and pressure ulcers is protective (OR 0.68, 95\% CI 0.43-0.95, P = 0.02 among the GG, GT and TT groups). Furthermore, we found that the VDR mRNA and protein expression levels in the subjects who carried the rs739837 GT and TT genotype were similar, and the number of subjects with the GT and TT genotypes groups was higher than the number of subjects with the GG genotype. Finally, we performed real-time PCR to validate the regulatory relationship between VDR and miR-885-3p and confirmed that the regulatory relationship between VDR and miR-885-3p was negative and that the index was -0.5034 . The results of the cellbased experiments provided evidence that the VDR was a direct target of miR-885, and the negative relationship between miR-885 and the VDR further confirmed the regulatory association between VDR and miR-885. The data from the patient samples indicated that the presence of the minor allele of the polymorphism showed a dominant model. Therefore, we performed the association study following a dominant model of the minor allele, and the results implied that the presence of the minor allele reduced the risk of pressure ulcers. The results of multiple analyses of VDR null mutant mice by different research groups are consistent, and the mice present similar phenotypes to those of a human hereditary, 


\section{Cellular Physiology Cell Physiol Biochem 2017;44:2129-2137 \begin{tabular}{ll|l} 
and Biochemistry Published online: December 12, 2017 & $\begin{array}{l}\text { C } 2017 \text { The Author(s). Published by S. Karger AG, Basel } \\
\text { www.karger.com/cpb }\end{array}$ \\
\hline
\end{tabular}

recessive, vitamin $\mathrm{D}$ deficiency disease, in which mutations in the VDR gene have been validated previously $[22,25,26]$. We then searched an online miRNA database (http:// www.bioguo.org/miRNASNP2/index.php) and found that miR-885-3p virtually targets the VDR and that one single nucleotide polymorphism (rs739837) located in the 3'UTR of VDR disrupts the binding between miR-885-3p and the VDR 3'UTR. Furthermore, when we conducted luciferase activity reporter assays in cells, we observed the luciferase activity only in the cells co-transfected with miR-885-3p, wherein rs739837-T VDR 3'UTR decreased significantly. However, the luciferase activity in the cells co-transfected with miR-885-3p and the rs739837-G VDR 3'UTR was comparable to that of the scramble control. To learn more about the regulatory relationship between miR-885-3p and VDR, we transfected cells with scramble control, miR-885-3p mimics or inhibitors, and VDR siRNA. We observed that the VDR protein (upper panel) and mRNA expression levels (lower panel) of the cells treated with miR-885-3p mimics and VDR siRNA were apparently lower than the those of the scramble control, and the results revealed an existing negative regulatory relationship between miR-885-3p and VDR.

The limitations of the present study were multiple. First, the sample size of the study was relatively small due to the time permitted and funding that was available for the sample collection. Second, animal models are absent from this study, and the current conclusion needs to be tested further in human tissue samples. A further population study with a larger sample size and a different genetic background is warranted. Further functional studies in animal models or human tissue samples are also needed to confirm the data that have been obtained from the current study.

\section{Conclusion}

Our findings showed different pressure ulceration morbidity for different rs739837 genotypes. We also found that the VDR was a virtual target of miR-885-3p and that a negative regulatory relationship existed between miR-885-3p and VDR. However, our study had several limitations. First, all participants enrolled were elderly, so whether our results can be applied to other populations needs further study. Second, we have only determined that the VDR is a virtual target of miR-885-3p and that a negative regulatory relationship exists between the two molecules. The specific mechanism remains unknown, further work is necessary to clarify how miR-885-3p and the VDR interact with each other.

\section{Disclosure Statement}

None.

\section{References}

1 Kalava UR, Cha SS, Takahashi PY: Association between vitamin D and pressure ulcers in older ambulatory adults: results of a matched case-control study. Clin Interv Aging 2011;6:213-219.

-2 Fogerty MD, Abumrad NN, Nanney L, Arbogast PG, Poulose B, Barbul A: Risk factors for pressure ulcers in acute care hospitals. Wound Repair Regen 2008;16:11-18.

Lyder CH: Pressure ulcer prevention and management. JAMA 2003;289:223-226.

Kuhn BA, Coulter SJ: Balancing the pressure ulcer cost and quality equation. Nurs Econ 1992;10:353-359.

5 Lyder CH, Ayello EA: Pressure Ulcers: A Patient Safety Issue; In Hughes RG (ed): Patient Safety and Quality: An Evidence-Based Handbook for Nurses. Rockville (MD): Agency for Healthcare Research and Quality (US), 2008, Chapter 12.

6 Russo CA, Steiner C, Spector W: Hospitalizations Related to Pressure Ulcers Among Adults 18 Years and Older, 2006: Statistical Brief \#64. In Healthcare Cost and Utilization Project (HCUP) Statistical Briefs. Rockville (MD): Agency for Healthcare Research and Quality (US), 2006-2. 


\section{Cellular Physiology Cell Physiol Biochem 2017;44:2129-2137 \begin{tabular}{l|l} 
DOI: 10.1159/000485952 & $\begin{array}{l}\text { O 2017 The Author(s). Published by S. Karger AG, Basel } \\
\text { www.karger.com/cpb }\end{array}$ \\
\hline
\end{tabular}

7 Plum LA, DeLuca HF: Vitamin D, disease and therapeutic opportunities. Nat Rev Drug Discov 2010;9:941955.

8 Krämer C, Seltmann H, Seifert M, Tilgen W, Zouboulis CC, Reichrath J: Characterization of the vitamin D endocrine system in human sebocytes in vitro. J Steroid Biochem Mol Biol 2009;113:9-16.

-9 Simpson RU, DeLuca HF: Characterization of a receptor-like protein for 1, 25-dihydroxyvitamin D3 in rat skin. Proc Natl Acad Sci U S A 1980;77:5822-826.

-10 Stumpf WE, Sar M, Reid FA, Tanaka Y, DeLuca HF: Target cells for 1, 25-dihydroxyvitamin D3 in intestinal tract, stomach, kidney, skin, pituitary, and parathyroid. Science 1979;206:1188-1190.

$\checkmark 11$ Hosomi J, Hosoi J, Abe E, Suda T, Kuroki T: Regulation of terminal differentiation of cultured mouse epidermal cells by 1 alpha,25-dihydroxyvitamin D3. Endocrinology 1983;113:1950-1957.

-12 He XJ, Ding Y, Xiang W, Dang XQ: Roles of 1, 25(OH)2D3 and Vitamin D Receptor in the Pathogenesis of Rheumatoid Arthritis and Systemic Lupus Erythematosus by Regulating the Activation of CD4+ T Cells and the PKC /ERK Signaling Pathway. Cell Physiol Biochem 2016;40:743-756.

13 Kato S: The function of vitamin D receptor in vitamin D action. J Biochem 2000;127:717-722.

14 Ambros V: The functions of animal microRNAs. Nature 2004;431:350-355.

15 Bartel DP: MicroRNAs: genomics, biogenesis, mechanism, and function. Cell 2004;116:281-297.

16 Bauersachs J, Thum T: Biogenesis and regulation of cardiovascular microRNAs. Circ Res 2011;109:334-347.

17 Gangaraju VK, Lin H. MicroRNAs: key regulators of stem cells. Nat Rev Mol Cell Biol 2009;10:116-125.

18 Lu J, Getz G, Miska EA, Alvarez-Saavedra E, Lamb J, Peck D, Sweet-Cordero A, Ebert BL, Mak RH, Ferrando AA, Downing JR, Jacks T, Horvitz HR, Golub TR: MicroRNA expression profiles classify human cancers. Nature 2005;435:834-848.

19 Stefani G, Slack FJ: Small non-coding RNAs in animal development. Nat Rev Mol Cell Biol 2008;9:219-230.

20 Denzer N, Vogt T and Reichrath J: Vitamin D receptor (VDR) polymorphisms and skin cancer. Dermatoendocrinol 2011;3:205-210.

-21 Fontaine J, Raynaud-Simon A: Pressure sores in geriatric medicine: the role of nutrition. Presse Med 2008;37:1150-1157.

22 Li YC, Pirro AE, Amling M, Delling G, Baron R, Bronson R, Demay MB: Targeted ablation of the vitamin D receptor: an animal model of vitamin D-dependent rickets type II with alopecia. Proc Natl Acad Sci U S A 1997;94:9831-9845.

23 Pang SM, Wong TK: Predicting pressure sore risk with the Norton, Braden, and Waterlow scales in a Hong Kong rehabilitation hospital. Nurs Res 1998;47:147-153.

24 Kennel KA, Drake MT, Hurley DL: Vitamin D deficiency in adults: when to test and how to treat. Mayo Clin Proc 2010;85:752-758.

25 Hughes MR, Malloy PJ, Kieback DG, Kesterson RA, Pike JW, Feldman D, O’Malley BW: Point mutations in the human vitamin D receptor gene associated with hypocalcemic rickets. Science 1988;242:1702-1705.

-26 Yoshizawa T, Handa Y, Uematsu Y, Takeda S, Sekine K, Yoshihara Y, Kawakami T, Arioka K, Sato H, Uchiyama Y, Masushige S, Fukamizu A, Matsumoto T, Kato S: Mice lacking the vitamin D receptor exhibit impaired bone formation, uterine hypoplasia and growth retardation after weaning. Nat Genet 1997;16:391-396. 